\author{
Military Technical College \\ Kobry El-Kobbah, \\ Cairo, Egypt
}

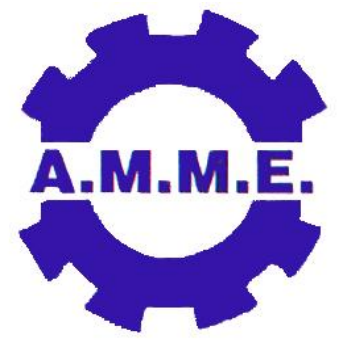

14th International Conference on

Applied Mechanics and

Mechanical Engineering.

\title{
The Effect of Crystallization and Ion Exchange to the SLS Glass for High-Strength Transparent Bulletproof Materials
}

\author{
By \\ Gyu-In Shim* Jaemin Lim* Hee-Jae Kim** Se-Young Choi*
}

\section{Abstract:}

A transparent bulletproof materials of soda-lime-silicate(SLS) glass has been ballistically tested after impacting by $5.45 \mathrm{~mm}$ AK-74 steel core projectiles at distance of 50 meters. The thickness of satisfaction on bulletproof test was about $30 \mathrm{~mm}$. For application of transparent bulletproof materials, the SLS glass was heated by crystallization and ion exchange. The Vickers hardness, fracture toughness, and bending strength of crystallized SLS glass was about $704 \mathrm{Hv}, 0.9409 \mathrm{MPa} \cdot \mathrm{m}^{1 / 2}$, and $452 \mathrm{MPa}$ which is about $24 \%, 31 \%$, $201 \%$ higher than parent SLS glass, respectively. The vickers hardness, fracture toughness, and bending strength of ion exchanged SLS glass was about $657 \mathrm{Hv}$, $0.7337 \mathrm{MPa} \cdot \mathrm{m}^{1 / 2}$, and $791 \mathrm{MPa}$ which is about $16 \%, 2 \%, 430 \%$ higher than parent SLS glass, respectively. Transmittance of heat treated and SLS glass was decreased slightly at the visible range. The results prove that light-weight bullet proof can be fabricated by crystallization and ion exchange technique of SLS glass.

\section{Keywords:}

SLS glass, crystallization, ion exchange, bulletproof 
* School of New Materials Science and Engineering, Yonsei University, Seoul, Korea

** Korea Military Academy, Department of Weapons Engineering, Seoul, Korea

\section{Introduction:}

Transparent bulletproof glass is an important material in the defense industry. Bulletproof glass protected human life from the bullets. SLS glass was the most common form of produced glass. SLS glasses generally have excellent chemical durability and thermal properties, but poor mechanical properties [1,2]. SLS glass was consisted of $73 \% \mathrm{SiO}_{2}$, $14 \% \mathrm{Na}_{2} \mathrm{O}, 9 \% \mathrm{CaO}, 0.15 \% \mathrm{Al}_{2} \mathrm{O}_{3}, 0.03 \% \mathrm{~K}_{2} \mathrm{O}, 4 \% \mathrm{MgO}, 0.02 \% \mathrm{TiO}_{2}, 0.1 \% \mathrm{Fe}_{2} \mathrm{O}_{3}$ $[3,5,6]$. The transition temperature $\left(T_{g}\right)$ and crystallization temperature $\left(T_{c}\right)$ were $564{ }^{\circ} \mathrm{C}$, $670{ }^{\circ} \mathrm{C}$, and thermal expansion coefficient $(\alpha)$ is $9.5 \mathrm{ppm} / \mathrm{K}$ at room temperature [4]. The hardness, fracture toughness, and bending strength of parent SLS glass were about 568 $\mathrm{H}_{\mathrm{v}}, 0.7190 \mathrm{MPa} \cdot \mathrm{m}^{1 / 2}$, and $150 \mathrm{MPa}$, respectively. For application of transparent bulletproof materials, SLS glass was heated by 2-step crystallization and ion exchange by employing screen printing technique in $\mathrm{KNO}_{3}$ powder.

\section{Experimental procedures:}

SLS glass was prepared from finished product (KCC, $3.5 \mathrm{~mm}$, Korea). For measurement of $T_{g}, T_{c(\max )}$, measured by differential thermal analysis (TG/DTA-92, Setaram, France). DTA run was performed for SLS glass powder by $5 \mathrm{~K} / \mathrm{min}$ heating rate. For measurement of the nucleation and crystal growth rates, glass samples were prepared 5 $\times 5 \times 3.5 \mathrm{~mm}^{3}$ and polished with SiC paper (\# 1,200 2,000). The nucleation and crystal growth rates were measured using two step heat treatment processes. SLS glass samples were heated at $5{ }^{\circ} \mathrm{C} / \mathrm{min}$ to the nucleation temperature between $525 \sim 625^{\circ} \mathrm{C}$, (intervals of $\left.25^{\circ} \mathrm{C}\right)$, then crystal growth was fixed at $700{ }^{\circ} \mathrm{C}(1 \mathrm{hr})$. The crystal growth temperatures ranged from $660 \sim 700{ }^{\circ} \mathrm{C}$ at intervals of $10{ }^{\circ} \mathrm{C}$. The nucleation condition was fixed at $575{ }^{\circ} \mathrm{C}$ for $1 \mathrm{hr}$. After cooling to the room temperature, crystallized glasses were determined to observe the number of nuclei $\left(\mathrm{N}_{\mathrm{A}}\right)$ by optical microscopy (Olympus BX2M, Japan). The number of nuclei per unit volume $\left(\mathrm{N}_{\mathrm{V}}\right)$ was calculated from [8]:

$$
N_{V}=\left(\frac{2}{\pi}\right) \cdot N_{A} \cdot Y
$$

where $N_{A}$ is the number of nuclei per unit area and $Y$ is the reciprocal of the mean diameter of nuclei. For all heat treated samples were excuted by X-ray differaction (D/max III, Rigaku, Japan) using Ni-filtered $\mathrm{CuK}_{\alpha}$ radiation. Hardness and fracture toughness were measured using a Vickers Microhardness Tester (MXD-CX3E, Matsuzawa, Japan). More than 10 indentations were made for each specimen with a 10 second loading time at a maximum load of $500 \mathrm{gf}$. The Vickers hardness was calculated from[1,7]:

$H_{V}=0.4636 \cdot\left(\frac{P}{a^{2}}\right)$ 
where $\mathrm{P}$ is the load of indentation, $a$ is the radius of indentation. The fracture toughness was calculated from[1,2]:

$$
K_{I C} \cdot \Phi / H_{V} \cdot a^{\frac{1}{2}}=0.15 \cdot K \cdot(c / a)^{-\frac{3}{2}}
$$

where $H_{v}$ is Vickers hardness, $\Phi$ is the restraint constant $(=3)$, and $a$ is the radius of indentation, $\mathrm{K}$ is a constant $(=3.2)$, and $\mathrm{c}$ is crack length. For measurement of the mechanical strength, 3-point bending strength was employed to the bar type specimens using Universal Testing Machine (H10K-C, Hounsfield, U.K.).

$\sigma=3 \cdot P \cdot L / 2 \cdot w \cdot t^{2}$

where $P$ is maxium load, $L$ is outside the interval , $w$ is width, $t$ is thickness. To measure 3point bending strength glass bars with diamensions of $3 \times 4 \times 36 \mathrm{~mm}^{3}$ were cut out from SLS glasses and polished. The $\mathrm{KNO}_{3}$ powder (Ducsan, Extra pure, Korea) was prepared for ion exchanged. For measurement of the depth profile for $\mathrm{Na}^{+}$and $\mathrm{K}^{+}$was prepared Electron Probe Micro Analyzer (EPMA, JXA-8900R, JEOL, Japan). Transmittance was measured using UV/VIS/NIR Spectrometer (Jasco, V-570, Japan). The scan speed and range of wavelength were $400 \mathrm{~nm} / \mathrm{min}$, in the range of $200 \sim 800 \mathrm{~nm}$.

\section{Results and discussion:}

Fig. 1 shows that the glass transition temperature $\left(T_{g}\right)$ and crystallization temperature $\left(T_{c}\right.$, max) were $575{ }^{\circ} \mathrm{C}, 680{ }^{\circ} \mathrm{C}$. The glass specimen was nucleated at $5{ }^{\circ} \mathrm{C} / \mathrm{min}$ to the temperature range of $525 \sim 625^{\circ} \mathrm{C}$ with intervals of $25{ }^{\circ} \mathrm{C}$ for $1 \sim 144 \mathrm{hr}$, and then crystallized at $700{ }^{\circ} \mathrm{C}$ for $1 \mathrm{hr}$. The crystal growth temperatures ranged from $660 \sim$

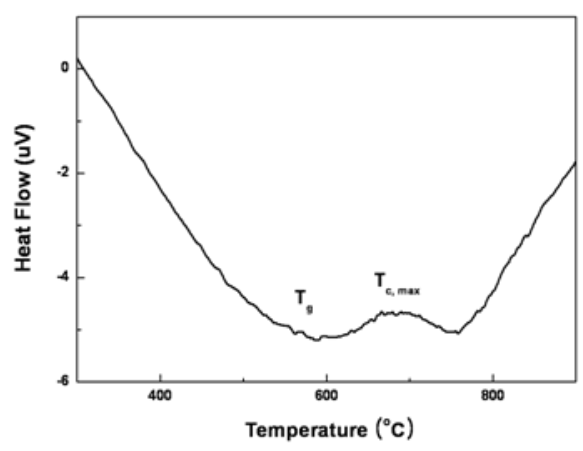

Figure (1): DTA curve of SLS glass at $5 \mathrm{~K} / \mathrm{min}$ heating rate 


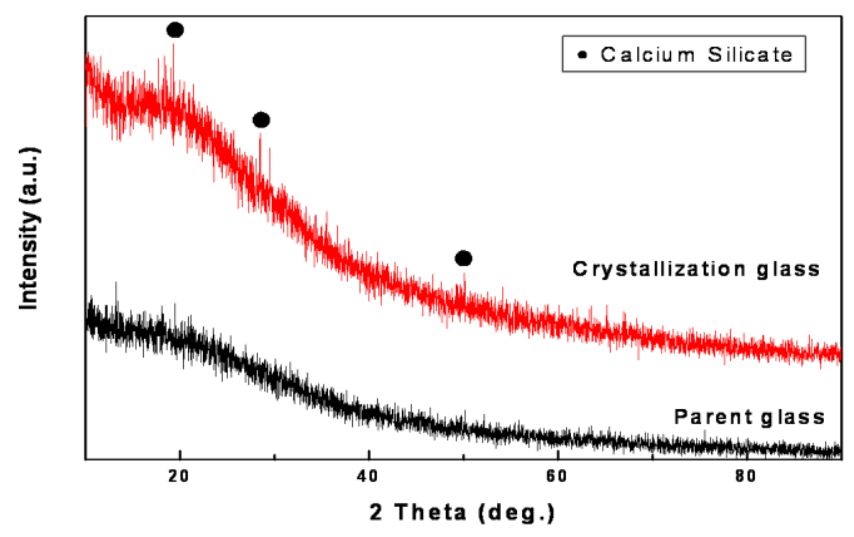

Figure (2): XRD patterns of parent and crystallized SLS glass(crystallization at $575{ }^{\circ} \mathrm{C}$ $\left./ 144 \mathrm{hr}, 650^{\circ} \mathrm{C} / 0.5 \mathrm{hr}\right)$

$700{ }^{\circ} \mathrm{C}$ at intervals of $10{ }^{\circ} \mathrm{C}$. The nucleation condition was fixed at $575^{\circ} \mathrm{C}$ for $1 \mathrm{hr}$. It is found from the XRD data in Fig. 2 that precipitation of calcium silicate is observed. Fig. 3, 4 exhibits the nucleation and crystal growth rate as a function of temperature. The maximum nucleation and crystal growth temperature are 575 and $680{ }^{\circ} \mathrm{C}$, respectively, and they have values of $3.8078 \times 10^{5} / \mathrm{mm}^{3} \mathrm{hr}$ and about $21 \mathrm{~nm} / \mathrm{min}$, respectively.

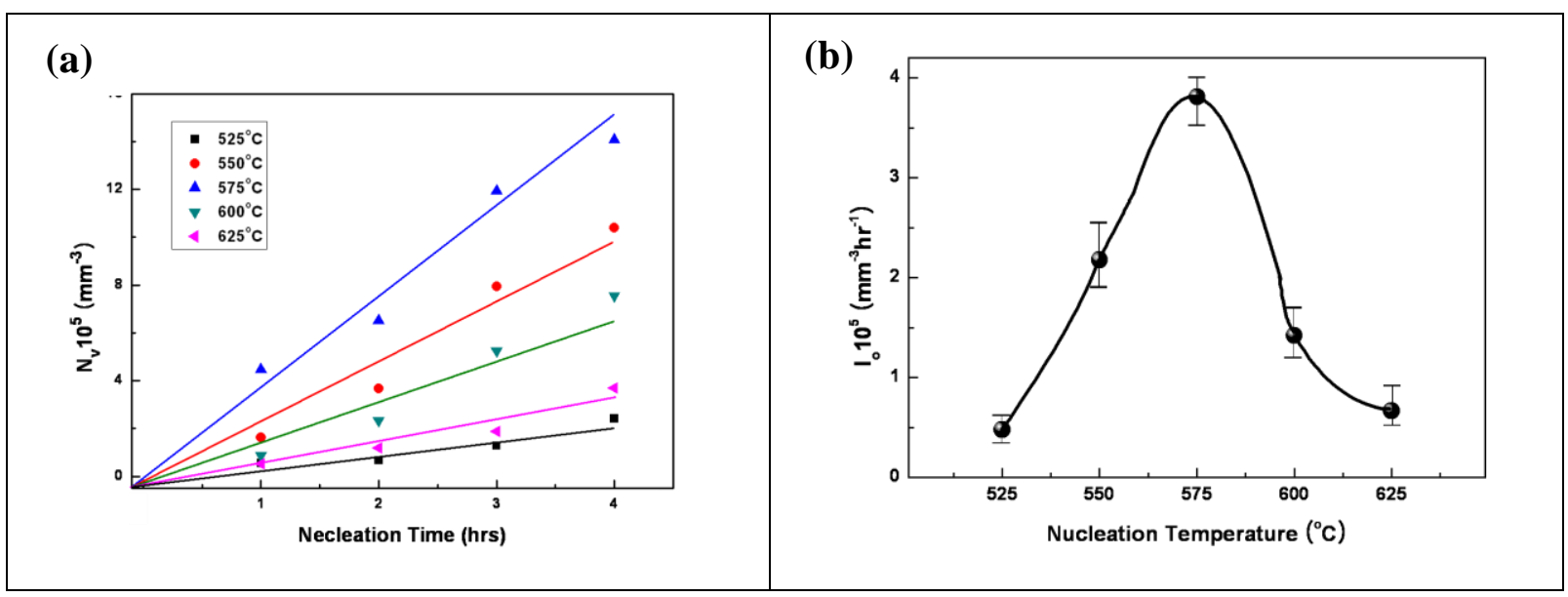

Figure (3): (a) Number of nuclei as a function of nucleation time(crystal growth at $700^{\circ} \mathrm{C}$, $1 \mathrm{hr})$, (b) Nucleation rates as a function of nucleation temperature for SLS glass

Fig. 5 shows that the change of nucleated number according to the nucleation time. The number of nuclei $\left(\mathrm{N}_{A}\right)$ was increasing with increasing the nucleation time from $162 / \mathrm{mm}^{2}$ (1 hr) to $567 / \mathrm{mm}^{2}$ (4 hr). Fig. 4 shows the crystal diameter as a function of crystal growth time. It is also found out that crystal diameters are increasing with increasing the crystal growth time from $477 \mathrm{~nm}\left(680^{\circ} \mathrm{C}\right.$ for $\left.15 \mathrm{~min}\right)$ to $821 \mathrm{~nm}\left(680^{\circ} \mathrm{C}\right.$ for $\left.60 \mathrm{~min}\right)$. 


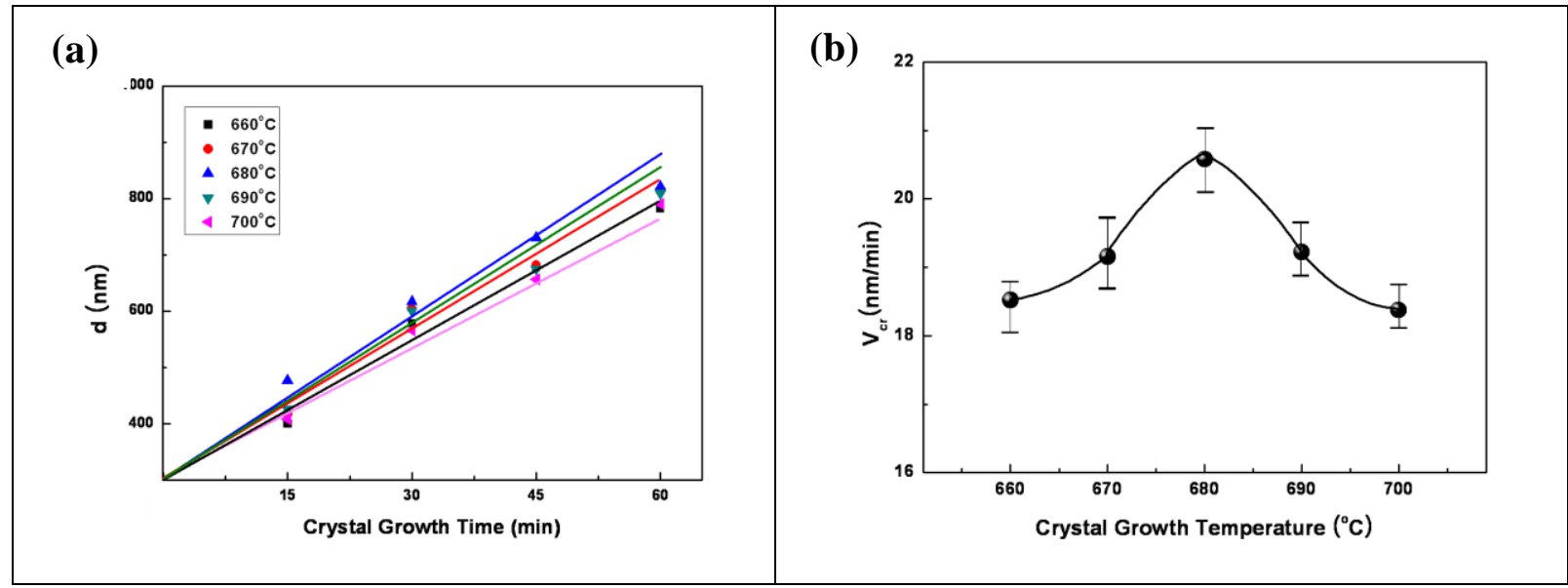

Figure (4): (a) Crystal diameter as a function crystal growth time for SLS glass (nucleation at $575^{\circ} \mathrm{C}, 1 \mathrm{hr}$ ), (b) Crystal growth rates as a function of temperature for SLS glass

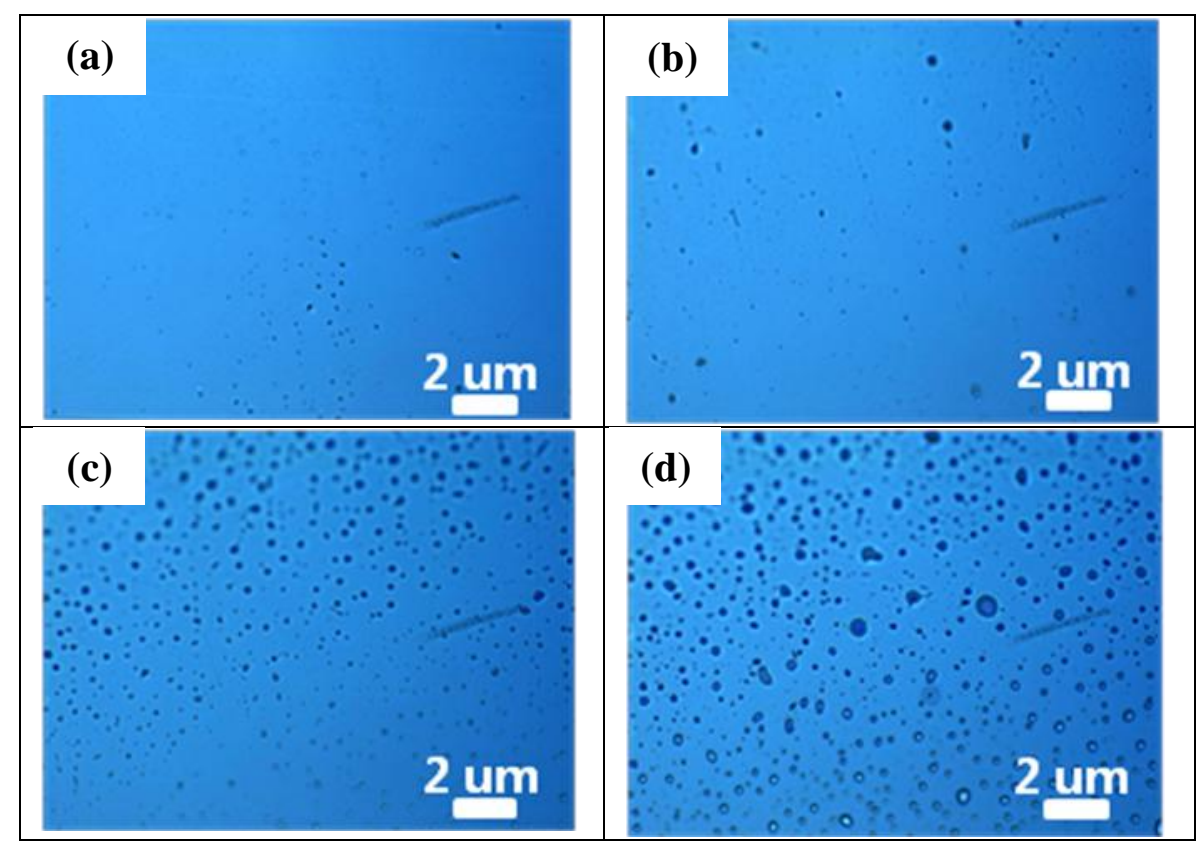

Figure (5): Optical microscope image of nucleated SLS glass at $575^{\circ} \mathrm{C}$ (a) 1, (b) 2, (c) 3 , and (d) $4 \mathrm{hr}$ (crystal growth at $700{ }^{\circ} \mathrm{C}$ for $1 \mathrm{hr}$ ).

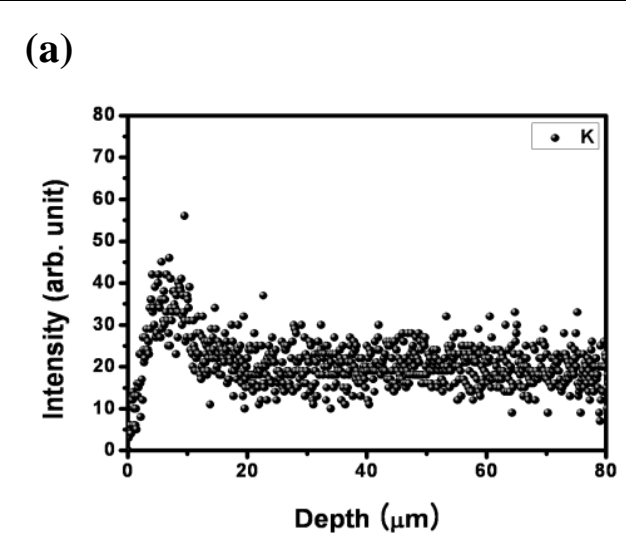

(b)

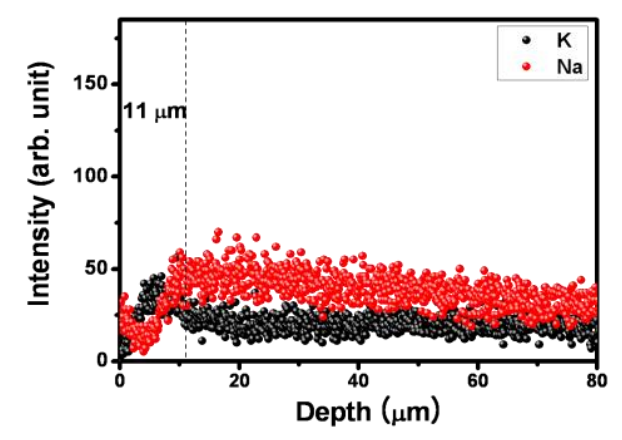




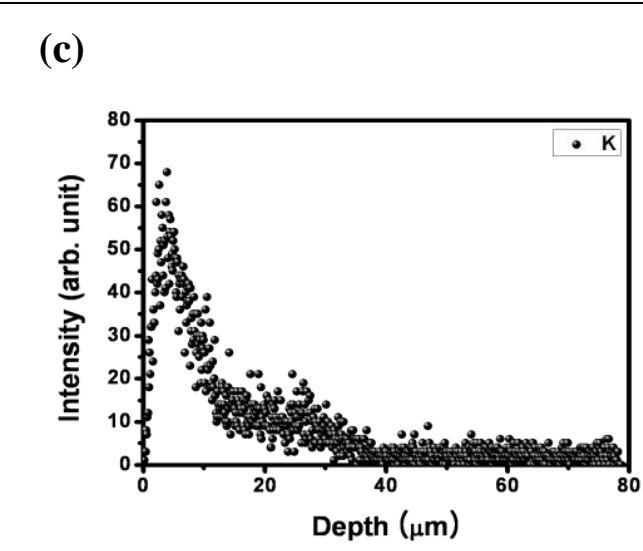

(d)

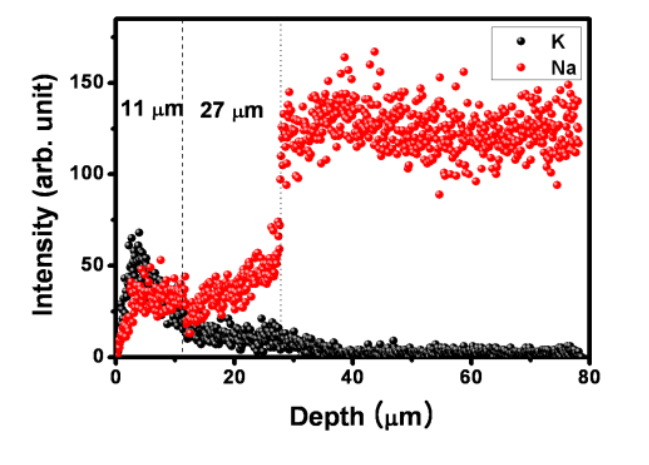

Figure (6): EPMA line profile of ion exchanged SLS glass by $\mathrm{KNO}_{3}$ powder $480{ }^{\circ} \mathrm{C}$ at for (a), (b) $10 \mathrm{~min},(\mathrm{c})$, (d) $30 \mathrm{~min}$

Fig. 6 shows that EPMA line profile for the ion exchanged SLS glass was treated in $\mathrm{KNO}_{3}$ powder containing different time. In this process, $\mathrm{K}^{+}, \mathrm{Na}^{+}$ion exchange takes place at the glass surface and creates a compressed stress which raise to the mechanical strength of the glass [3]. With the increasing heat-treatment time from $10 \mathrm{~min}$ to $30 \mathrm{~min}$, the depth profile was increasing from $11 \mu \mathrm{m}$ to $38 \mu \mathrm{m}$, but mechanical properties were reduced (Fig. 8). It was also found out that excessive heat treatment brings about stress relaxation [2]. Therefore, we have to find the best conditions of ion exchange according to the temperature and time. Fig. 7, 8 shows that mechanical properties of crystallized and ion exchanged SLS glass. The mechanical properties of crystallized SLS glass were increased by increasing the nucleation time. Because of the crystallized SLS glass was increased by increasing density by crystal phase.

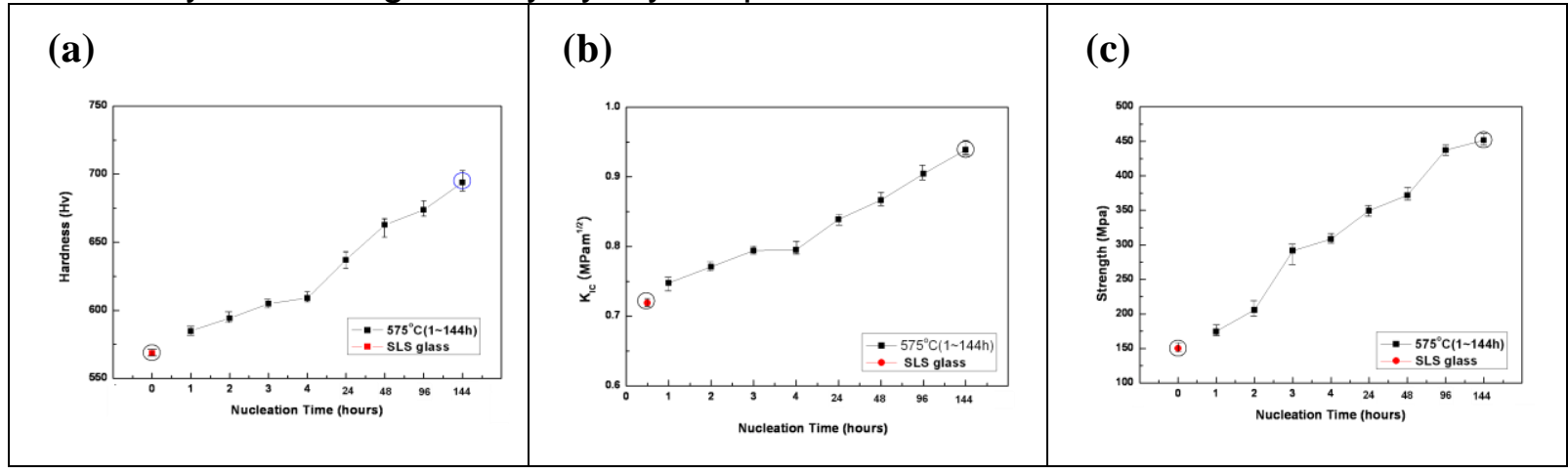

Figure (7): Hardness, Fracture toughness, and Strength of crystallized SLS glass at various nucleation times(crystal growth at $650^{\circ} \mathrm{C}$ for $0.5 \mathrm{hr}$ ) 


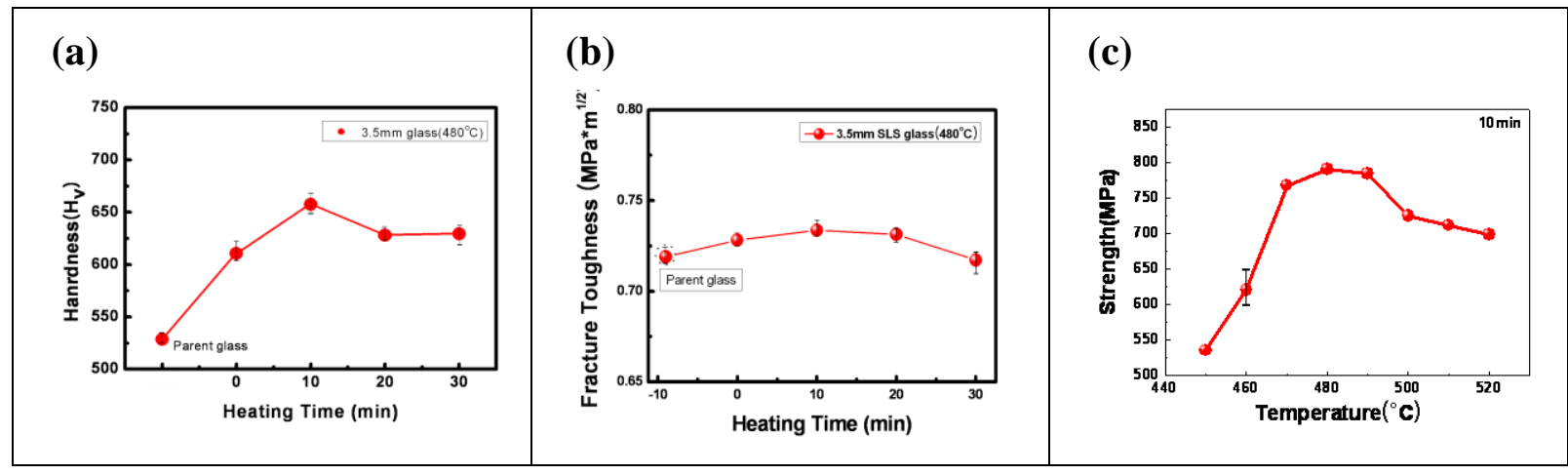

Figure (8): Hardness, Fracture toughness, and Strength of ion exchanged SLS glass at various time, temperature

The Vickers hardness, fracture toughness, and bending strength of crystallized SLS glass (at $575{ }^{\circ} \mathrm{C}$ for $144 \mathrm{hr}, 650^{\circ} \mathrm{C}$ for $0.5 \mathrm{hr}$ ) were about $704 \mathrm{H}_{\mathrm{v}}, 0.9409 \mathrm{MPa} \cdot \mathrm{m}^{1 / 2}$, and 452

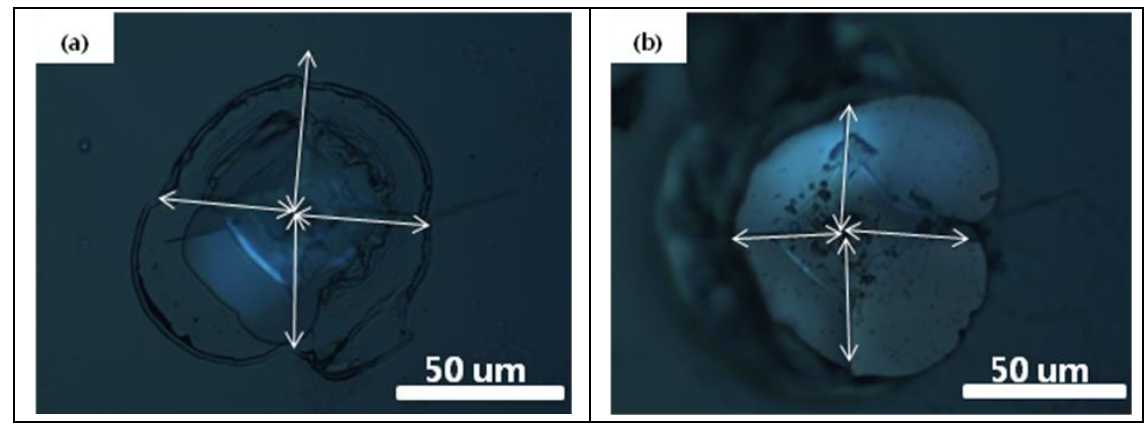

Figure (9): Crack length of SLS glass. (a) parent SLS glass, (b) crystallized SLS glass at $575^{\circ} \mathrm{C}$ for $144 \mathrm{hr}, 650^{\circ} \mathrm{C}$ for $0.5 \mathrm{hr}$

MPa which is about $24 \%, 31 \%, 201 \%$ higher than parent SLS glass, respectively. The crack length of parent and crystallized SLS glass were 52.7 um, 50.3 um, respectively. The result revealed that the crack length was increasing of hardness, fracture toughness of glass (Table 1).

Table (1): Mechanical properties of crystallized SLS glass at various nucleation times(crystal growth at $700{ }^{\circ} \mathrm{C}$ for $1 \mathrm{hr}$ )

\begin{tabular}{|c|c|c|c|c|}
\hline & $\begin{array}{c}\text { Nucleation } \\
\text { Time } \mathbf{( h r})\end{array}$ & $\begin{array}{c}\text { Hardness } \\
\left(\mathbf{H}_{\mathbf{v}}\right)\end{array}$ & $\begin{array}{c}\text { Fracture } \\
\text { Toughness } \\
\left(\mathbf{M P a} \cdot \mathbf{m}^{\mathbf{1}} \mathbf{2}\right)\end{array}$ & $\begin{array}{c}\text { Strength } \\
\mathbf{( M P a )}\end{array}$ \\
\hline \hline Parent glass & 0 & 568.7 & 0.7190 & 150 \\
\hline & 1 & 584.8 & 0.7480 & 174 \\
\cline { 2 - 5 } Crystallized & 2 & 594.2 & 0.7715 & 205 \\
\cline { 2 - 5 } SLS glass & 3 & 604.9 & 0.7896 & 291 \\
\cline { 2 - 5 } & 4 & 609.0 & 0.7917 & 308 \\
\hline
\end{tabular}

The Vickers hardness, fracture toughness, and bending strength of ion exchanged SLS glass (at $480{ }^{\circ} \mathrm{C}$ for $10 \mathrm{~min}$ ) were about $657 \mathrm{H}_{\mathrm{v}}, 0.7337 \mathrm{MPa} \cdot \mathrm{m}^{1 / 2}$, and $791 \mathrm{MPa}$ which is about $16 \%, 2 \%, 430 \%$ higher than parent SLS glass, respectively. 


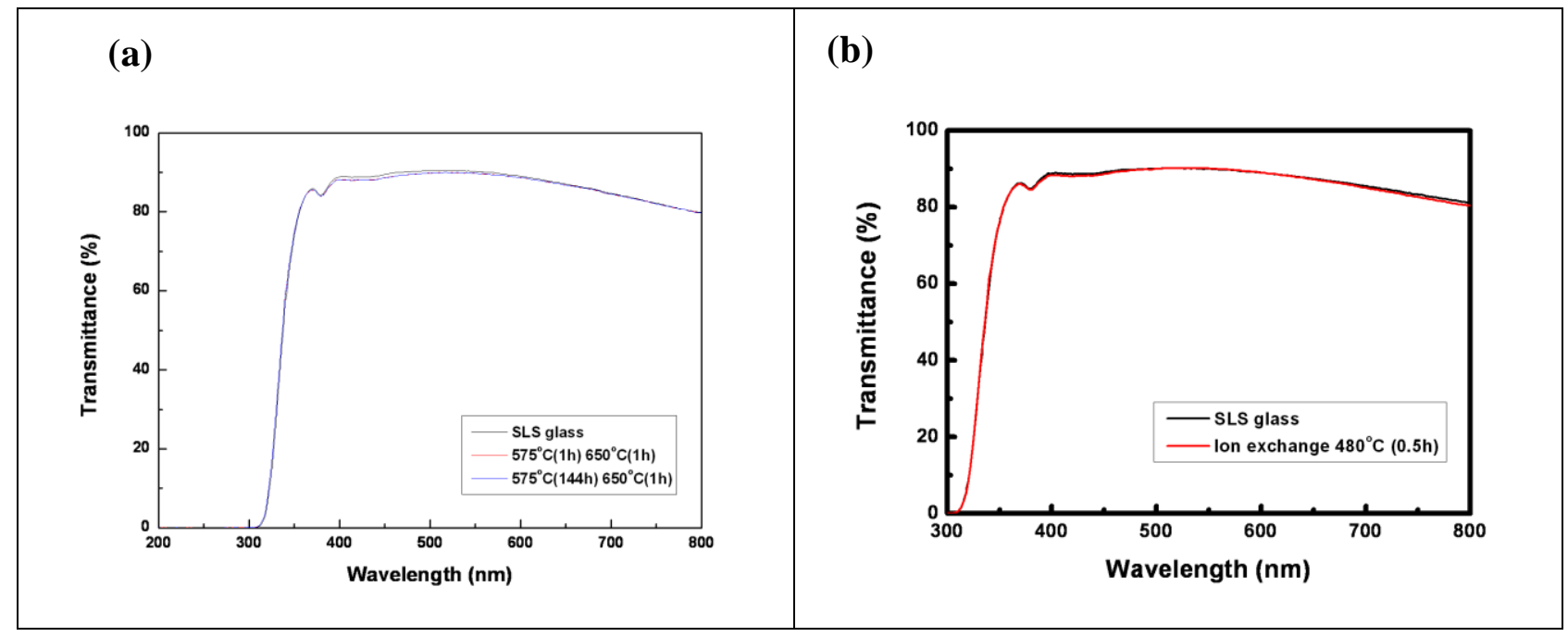

Figure (10): Transmittance of crystallized and ion exchanged SLS glass

Transmittance of ion exchanged and crystallized SLS glass was decreased slightly (within $0.5 \%)$. The visible transmittance was decreased with increasing crystal size. It is evident that the gradual decrease of visible transmittance is due to light scattering from the crystal phase particles. Scattering was increased with increasing crystal size.

\section{Conclusions:}

For application in light-weight bulletproof glass, SLS glass was strengthened by crystallization and ion exchange. Properties of crystallized and ion exchanged glass heated at different conditions were examined. As a result, The vickers hardness, fracture toughness, and bending strength of crystallized SLS glass (at $575^{\circ} \mathrm{C}$ for $144 \mathrm{hr}, 650^{\circ} \mathrm{C}$ for $0.5 \mathrm{hr}$ ) were about $704 \mathrm{H}_{\mathrm{v}}, 0.9409 \mathrm{MPa} \cdot \mathrm{m}^{1 / 2}$, and $452 \mathrm{MPa}$ which is about $24 \%, 31 \%$, $201 \%$ higher than parent SLS glass, respectively. And Vickers hardness, fracture toughness, and bending strength of ion exchanged SLS glass (at $480^{\circ} \mathrm{C}$ for $10 \mathrm{~min}$ ) were about $657 \mathrm{H}_{\mathrm{v}}, 0.7337 \mathrm{MPa} \cdot \mathrm{m}^{1 / 2}$, and $791 \mathrm{MPa}$ which is about $16 \%, 2 \%, 430 \%$ higher than parent SLS glass, respectively. Transmittance of ion exchanged and crystallized glass were decreased slightly at the visible range. A transparent bulletproof materials of sodalime-silicate (SLS) glass has been ballistically tested after impacting by $5.45 \mathrm{~mm}$ AK-74 steel core projectiles at distance of 50 meters. The thickness of bulletproof materials were about $30 \mathrm{~mm}$ (Korea Military Academy). It can be expected of transparent bulletproof materials in more light-weight and thinner (over $10 \sim 15 \%$ ) by ion exchange and crystallization.

\section{Acknowledgements:}

This work is supported by the Defence Nano Technology Application Center

\section{References:}

[1] M. Suszy, L. Krajczyk and Z. Mazurkiewicz, TEM studies of silver nanoparticles in phase-separated soda lime silicate glasses, Materials Chemistry and Physsics, Vol. 81, P. 404-406, 2003.

[2] M. Roskosz, M. J. Toplis and P. Richet, Kinetic vs. thermodynamic control of crystal nucleation and growth in molten silicates, Journal of Non-Crystalline Solid, Vol. 352, P. 180-184, 2006. 
[3] A. Abd El-Moneim, Quantitative analysis of elastic moduli and structure of B2O3$\mathrm{SiO} 2$ and Na2O-B2O3-SiO2 glasses, Physica B, Vol. 325, P. 319-332, 2003.

[4] S. B. Sohn and S. Y. Choi, Crystallization behavior in the glass system $\mathrm{MgO}-\mathrm{Al}_{2} \mathrm{O}_{3}-$ $\mathrm{SiO}_{2}$ :influence of $\mathrm{CeO}_{2}$ addition, Journal of Non-Crystalline Solid, Vol. 282, P. 221227, 2001.

[5] S. B. Sohn, Y. K. Lee, S. Y. Choi, Controlled crystallization and characterization of cordierite glass-ceramics for magnetic memory disk substrate, Journal of Materials Science, Vol. 35, P. 4815-4821, 2000.

[6] Z. Xiangchen, H. Ouli, X. Cengzuo and Z. Yinghuan, The Effect of Impurity lons Molten Salt $\mathrm{KNO}_{3}$ on lon-Exchange and Strengthrning of Glass, Journal of NonCrystalline Solid, Vol. 80, P. 313-318, 1986.

[7] I. Fand, Influence of crystallization on some properties of $\mathrm{ZrF}_{4}-\mathrm{BaF}_{2}-\mathrm{YF}_{3}-\mathrm{AlF}_{3}$ glasses, Journal of Non-Crystalline Solid, Vol. 129, P. 133-136, 1991.

[8] V. P. Pukh, L. G. Baikova, M. F. Kireenko, L. V. Tikhonova, T. P. Kazannikova, and A. B. Sinani, Atomic Structure and Strength of Inorganic Glasses, Physis of the Solid State, Vol. 47, No. 5, P. 876-881, 2005. 